\title{
The Global Paleo-Vegetation Project (BIOME 6000)
}

\author{
Jena , Germany, October 6-10, 1998
}

The Global Paleo-Vegetation Project (BIOME 6000) was initiated at a workshop in Hörby, Sweden in 1994 under the joint auspices of IGBP-GAIM, IGBPDIS, IGBP-GCTE and IGBP-PAGES. The aim of BIOME 6000 was to assemble pollen data for 6000 and 18,000 years before present (yr B.P.), and to use these data to construct global maps of vegetation for these time periods, using a standard, objective "biomisation" technique based on the classification of plant taxa into plant functional types.

Although there have been several BIOME 6000 workshops, focussing on assembling and creating regional $\mathrm{BIO}-$ ME 6000 data sets, the workshop recently held in Jena was the first opportunity for the BIOME 6000 community to meet since its inauguration. The Jena meeting had two goals: (a) to review the progress that had been made towards producing global biome maps for 6000 and 18,000 yr B.P., and (b) to review future applications of the technology and very extensive data sets being developed by the project.

Reports on the state of the regional BIOME 6000 data sets were presented for Beringia (Mary Edwards), the Western USA (Kathy Anderson), Eastern and Boreal North America (Jack Williams), Europe (Joel Guiot), Russia and central Asia (Pavel Tarasov), South America (Rob Marchant and Henry Hooghiemstra), Africa (Dominique Jolly), Japan (Shinya Sugita), China (Ge Yu) and Southeast Asia-Australasia (Geoff Hope and Liz Pickett). These reports made it clear that the biomisation technique provides robust reconstructions of the modern vegetation, across a wide range of climates and vegetation types and even in regions significantly impacted by human activity. Biome maps for 6000 and 18,000 yr B.P. have been produced for most regions of the globe. The biomisation of the remaining regions (specifically South America and the Southeast Asia-Australasia regions) is being very actively pursued, and biome maps for these regions are expected to be ready during the winter of 1998/ 1999.

The BIOME 6000 project was originally envisaged as providing data sets that could be used for model evaluation within the IGBP-GAIM "6000 yr B.P. experiment" (an initiative to quantify the importance of biophysical feedbacks in the climate system) and within the Paleoclimate Modelling Intercomparison Project (PMIP). Sandy Harrison gave an update on progress within PMIP and showed how the BIOME 6000 data set for Africa had already been used to demonstrate that model-simulated changes in the African monsoon in response to orbital forcing were too small to explain the observed vegetation changes. Presentations by Colin Prentice, John Kutzbach and Claudia Kubatzki, reporting on work carried out within the GAIM "6000 yr B.P. experiment" and within the TEMPO (Testing Earth system Models with Paleoenvironmental Observations) project, made it clear that it will be necessary to incorporate feedbacks due to ocean- and/or land-surface changes in order to simulate the observed enhancement of the African monsoon more realistically. Ocean and land-surface feedbacks are also implicated in the correct simulation of e.g. the Asian monsoon and high-latitude summer warming during the midHolocene, and northern hemisphere mid-latitude cooling and the expansion of deserts at the last glacial maximum. The BIOME 6000 data set will, of course, be an important resource to evaluate planned coupled atmosphere-oceanbiosphere model experiments which incorporate such feedbacks.

However, as several presentations made clear, model evaluation is not the only task to which the BIOME 6000 approach can be usefully applied. Bob Thompson showed results of the biomisation of pollen and plant-macrofossil data from western North America for multiple time periods, and how these results could be used to document the evolution of vegetation since the glacial maximum. Joel Guiot and Shinya Sugita demonstrated alternative methods that could be used to make quantitative climate reconstructions from biomised data. Joel Guiot also discussed ways in which the biome data at individual sites could be spatially generalised in order to derive gridded maps of land-surface conditions which could be used to specify land-surface characteristics in model simulations. Although these approaches have been developed with data sets for specific regions, they could be applied globally.

The existing BIOME 6000 data sets, and the additional applications of BIOME 6000 data and methodology demonstrated at the workshop, could contribute significantly to a number of IGBP initiatives. The potential links between BIOME 6000 and some of these initiatives were explored in presentations by John Dodson (the Pole-Equator-Pole transects), Rachid Cheddadi (European Pollen Data Base), Louis Francois (the Paleo-Carbon Cycle Modelling Intercomparison Project), Sheila Hicks (CAPE: Circum-Arctic Paleo-Environments), Matt Duvall (PALE: Paleoenvironments of Arctic Lakes \& Estuaries), Ralph Schneider (IMAGES), Frank Oldfield (Global Land Cover), and Colin Prentice (GAIM Paleo Trace Gas and Mineral Aerosols Challenge).

The Jena meeting amply demonstrated that the BIOME 6000 project is alive, well and on target to achieve its goal of producing global vegetation maps for 6000 and 18,000 yr B.P. in 1999. The success of the project is largely due to a very extensive collaboration, now involving more than 150 scientists worldwide. The first fruits of this international collaboration, in the form of biome maps for individual regions, are being published in three special issues of the Journal of Biogeography during 1998-1999. However, the demonstration of new applications of the BIOME 6000 approach and the lively discussions at the Jena meeting indicate that we can expect an even richer, long-term scientific harvest from BIOME 6000.

Our thanks go to the German IGBP Secretariat for their support of this meeting and to IGBP-GAIM, IGBP-DIS and the MPG for providing the funding that made it possible.

\footnotetext{
Sandy P. Harrison and I. Colin Prentice Max Planck Institute for Biogeochemistry, Jena, Germany

sandy.harrison@bgc-jena.mpg.de colin.prentice@bgc-jena.mpg.de
} 